\title{
Learners' and Instructors' Views on Technology Supported Engineering Education: Initial Outcomes in a Cross-cultural Study Sample
}

\author{
Firat Sarsar ${ }^{1}$, Özge Andiç Çakir", ${ }^{2, *}$ María José Bohórquez ${ }^{3}$, Manon Van Leeuwen ${ }^{4}$ \\ ${ }^{1}$ Department of Computer Education and Instructional Technology, Faculty of Education, Ege University, 35100, İzmir, Turkey \\ ${ }^{2}$ Department of Civil Engineering, Engineering Faculty, Ege University, 35100, İzmir, Turkey \\ ${ }^{3}$ Consorcio para la Gestión del Instituto Tecnológico de Rocas Ornamentales y Materiales de Construcción (INTROMAC), \\ Campus Universitario, 10071, Cáceres, Spain \\ ${ }^{4}$ EOLAS, S.L. Carretera de Sevilla Km6, 06080, Badajoz, Spain
}

Copyright $(2018$ by authors, all rights reserved. Authors agree that this article remains permanently open access under the terms of the Creative Commons Attribution License 4.0 International License

\begin{abstract}
This exploratory and cross-cultural mixed method study aimed to understand the perspectives of learners and instructors in engineering education on mobile learning and information and communication technology (ICT) tools in different countries. A total of 197 participants attended the survey for understanding perspectives of mobile learning in engineering education: 54 participants from Belgium, 36 participants from the Netherlands, 41 participants from Spain and 66 participants from Turkey, respectively. Data was collected via (i) surveys, (ii) open-ended questionnaires, and (iii) semi-structured focus group interviews, respectively. The results showed that most of the learners preferred to use a mobile education application in their native language. The learners mentioned that they preferred to learn by videos and audios; similarly, according to the instructors' data, most of the instructors preferred to teach with videos as their favorite learning tool. However, using educational technological tools is limited by instructors' lack of experience. It is very important to overcome the fear related to using new technologies in the classroom and increase the readiness of using educational tools by integrating them into their courses effectively. It is strongly recommended that digital learning materials collected in a virtual environment should be accessible to instructors and learners.
\end{abstract}

Keywords Mobile Learning Technologies, ICT Tools, Distance Education, Needs Analysis

\section{Introduction}

In parallel with the global megatrends [1] that accelerate the industrial and societal growth such as, new and sustainable resources for production, changing (environmentally responsible and digitally-driven) societies, leading to emerging markets of open innovation, engineering education has drifted towards evolving new opportunities and its own trends [2,3]. Today, engineers and technologists confront socio-scientific issues as described above and they focus on increasing their soft (people) skills while pursuing technical innovations which progress rapidly. Moreover, students' entrepreneurial capacity is aimed to be supported, and this can be achieved by training engineers for being not only technically able, but by making them gain creativity skills and enable them to work well in multidisciplinary teams [4,5]. Furthermore, engineering education requires practice-intensive training and some of the basic needs are preparing students for work life, introducing them the most realistic engineering problems and improving their thinking system on possible solutions.

A review study by Viegas et al. [6] shows that in order to overcome the 21 st century challenges the following actions are expected;

- $\quad$ boosting engineering and technology-based learning to improve engineering professionally and to improve social and scientific competencies,

- $\quad$ making a detailed analysis of graduate engineering students' competencies versus needs of professionals in the sector,

- $\quad$ planning for engineering education and internships regarding the successful practices between academia and industry and,

- considering engineering education from a multicultural point of view.

Moreover, considering all those emerging trends 
mentioned above, digital literacy, translating into teaching has gained importance for higher education instructors, thus it is offering more possibilities for contributing to students' digital learning $[7,8]$.

Applying all the above-mentioned aspects successfully in the classroom may only be possible by inclusion and adoption of ICT tools. This has also been understood by policy-makers, for instance the European Higher Education Area (EHEA) includes digitalization in its agenda and in January 2018 the European Commission adopted a Digital Education Action Plan [9] which includes 11 actions to support technology-use and digital competence development in education.

When looking more closely at the digital tools used for engineering education, Web 2.0 tools such as MOOCs and mobile learning tools for portable devices are among the most widely used ones. These tools include digital learning materials in the format of audio, video, 3D model and augmented reality (AR) and virtual reality (VR) applications \& software applications [10,11] of e-learning. Using digital learning materials such as animations, graphics, simulations, drawings and laboratory applications have been found efficient for engineering education [12]. Using ICT tools in a more traditional learning environment makes the learning experience more open, authentic and it extends educational opportunities, while at the same time teaching students how to deal with large amounts of information and how to gain more autonomy over their learning processes.

Today, the generation brought up with internet, digital games and smartphones, is known as "digital natives, millennials or digital learners" [13]. They are more interested and skilful in accessing and researching digital information, open to communication via social media and more creative in contributing to contents on the internet. Jadhav et al. [14] in their study concluded that flipped classroom method helped engineering students to go with their pace of learning and improved their problem-solving capability. Martin et al. [15] analysed methodologies in learning which may contribute to developing digital competences in engineering education, in their case, telecommunication. They developed a course with gamification and online quiz experiences and found out that the students were more satisfied with the digital learning experience. They concluded that digital transformation processes may be led forth by proper education techniques for engineering students and corresponding employers' needs for the digital-driven sectors. A study in China by Long, Zhang et al. [16] shows that MOOCs were extensively used in colleges and universities, but despite its innovative aspect as an education technique, its application to engineering education as a simulation of the classroom was found to be limited for introducing the applied knowledge which can only be possible by hands-on application.

Thanks to developments in educational technologies, interactive ICT environments including high quality visual digital learning materials can be said to have become a supporting part of the engineering education [17]. Nevertheless, the above literature findings indicate that before designing ICT environments and learning materials for engineering education a comprehensive analysis based on the needs of students, instructors and the sector should be performed.

The present study is based on the findings of the needs-analysis of the nEBULA project $[18,19]$, whose outputs were aimed at providing higher education students and professionals in the areas of building and energy efficient construction, with a mobile learning platform to develop their skills and competences to upfront energy-efficient building retrofitting projects. The platform has been developed as an ICT tool which enables users to access knowledge while they are mobile.

\section{Methodology}

This mixed method exploratory study was designed to understand the perspectives of learners and instructors in engineering education on mobile learning technologies and ICT learning tools in different countries. Three main data collecting tools were employed for both instructors and learners in this study. These are (i) surveys, (ii) open-ended questionnaires, and (iii) semi-structured focus group interviews. All data collecting tools were created by the authors of this study according to experts' views in the field of education and engineering. Since it is a cross-cultural study, data collecting tools created in English were translated into 4 different languages with language experts to increase their validity. In addition, each country had small groups to validate their translated surveys. The final versions of each data collection tool in each country were agreed by researchers' team before final application phase started.

\section{With the (i) Surveys}

The learners were questioned with respect to;

- Awareness on mobile learning technologies; if they ever had a previous experience of a mobile platform for learning as a digital learning material

- Preferred ICT tools, which ICT tools they would prefer to use for learning,

- Preferred language; in which language they prefer learning.

The instructors were questioned with respect to;

- Awareness on mobile learning technologies, if they ever had a previous experience of a mobile platform either for teaching or learning,

- Preferences on mobile learning technologies; if they would like to use a mobile learning technologies (supportive) for their courses or not, 
- ICT tool preferences, which ICT tools they would prefer to use for learning,

- Language preferences; in which language they prefer learning.

With (ii) open-ended questionnaires and (iii) semi-structured focus group interviews;

The learners were questioned to understand their thoughts on ICT technologies. The instructors were also questioned about their background knowledge and skills on ICT tools and mobile technologies, on the other hand they were questioned if they would like to use mobile learning technologies for their courses and if they would like to develop and share course materials for this purpose.

Content analysis was employed for analysing the qualitative data. The data analysis was completed separately in each country and results were discussed together to decide the way of coding effectively. As a result of those discussions, the main and common themes of codes were created, and codes were put under each theme. The codes which weren't fitted or suited to any of those themes due to cultural differences of perspectives were coded separately.

\section{Target Group Selection \& Participants}

Part of the project nEBULA was designing an e-learning application for students and young professionals to improve their competence and knowledge in energy efficient retrofitting in construction sector. Thus, the study focused on developing an efficient platform to reach this aim considering the views of learners and teachers, choosing relevant learning technologies and course materials. Three higher education institutes and a VET institute from four different countries among different regions of Europe led the research in their respective countries.

Every participant entity identified a list of instructors from their institutions giving courses in the relevant subjects of energy efficient building retrofitting, with different backgrounds. The online-surveys were sent to all instructors listed, and the responses taken were analysed. The focus group of instructors were selected randomly from the above group and they were asked to apply the survey to their students during the course they are instructing. The focus group students were also selected randomly.

A total of 197 persons participated in the survey aimed at understanding perspectives of mobile learning technologies for engineering education, 145 of them were learners and the rest were instructors. The distribution of participants are as follows, 54 persons from Belgium, 36 persons from the Netherlands, 41 persons from Spain and 66 persons from Turkey, respectively (See Table 1). Demographic distribution of participants reveals that $76 \%$ of the participants were male and $23 \%$ of the participants were female. Among them, $85 \%$ of students aged between
$17-24$ and $15 \%$ aged between $24-34$, whereas $21 \%$ aged between $25-34,45 \%$ between $35-44$ and $34 \%$ between 45-64, respectively. Five learners and five instructors were selected for semi-structured focus group interviews from each country.

The values represented in Table 1 are the numbers of participants the values in parenthesis represents the percentage of each value to the total number of participants attended the survey.

Table 1. Number of participants (learners and instructors) involved in this study, grouped according to country

\begin{tabular}{|c|c|c|}
\hline Countries & Learners n(\%) & Instructors n(\%) \\
\hline Belgium & $36(18 \%)$ & $18(9 \%)$ \\
\hline The Netherlands & $26(13 \%)$ & $10(5 \%)$ \\
\hline Spain & $33(17 \%)$ & $8(4 \%)$ \\
\hline Turkey & $50(25 \%)$ & $16(8 \%)$ \\
\hline
\end{tabular}

\section{Results}

\subsection{Analysis of Surveys}

Learners were asked if they had previous experience with using mobile learning technologies and the results (see Table 2) show that there is a general awareness with regards to the mobile learning technologies. It can be said that $57 \%$ of total learners have tried using mobile learning technologies. This percentage is almost $78 \%$ for Belgium where most of the learners have used those technologies previously. However, this result is higher than other countries such as Turkey and Spain where around $48 \%$ of learners and such as Netherlands where $54 \%$ of learners have used those technologies for learning.

Table 2. Mobile Learning Technologies Experience of Learners by Country

\begin{tabular}{|c|c|c|c|}
\hline Countries & Yes & No & No Idea \\
\hline Belgium & 28 & 4 & 4 \\
\hline The Netherlands & 14 & 11 & 1 \\
\hline Spain & 16 & 13 & 4 \\
\hline Turkey & 24 & 20 & 6 \\
\hline
\end{tabular}

The learners were asked which ones they would prefer for learning among digital learning materials such as videos, audios, educative games, etc. (See Table 3). Interestingly, the learners from all countries like to learn through videos and audios mainly. ICT tools such as, social networks/forums, wikis, blogs, e-books, educative games are the other preferred tools for digital learning. According to Table 2, as expected, learners in Belgium listed more tools as they have already practiced more in learning environments. Thus, $78 \%$ of Belgium learners use mobile learning technologies more than other countries; their experiences using digital tools in learning are 
quantitatively higher than those countries. It is also important to mention that videos and audios are the main digital learning tools according to results of learners' data which might show the limitations in a variety of digital course materials.

Table 3. ICT Tools Preferred by Learners

\begin{tabular}{|l|l|}
\hline Countries & Learners \\
\hline Belgium & $\begin{array}{l}\text { video, audio, social networks, wikis, blogs, } \\
\text { podcasts, educative games }\end{array}$ \\
\hline The Netherlands & $\begin{array}{l}\text { video, e-book, audio, social network/forums, } \\
\text { wiki tools }\end{array}$ \\
\hline Spain & videos, audios, social networks/forums \\
\hline Turkey & $\begin{array}{l}\text { videos, blogs, social networks/forums, } \\
\text { e-books, wiki tools }\end{array}$ \\
\hline
\end{tabular}

Instructors were asked if they have ever experienced using mobile learning technologies before. The mobile learning technologies experiences of instructors are not as optimistic as with regards to the learners. The results showed that approximately $20 \%$ of instructors have used mobile learning technologies previously. Interestingly, 63\% of Spanish instructors indicated that they used mobile technologies in their classroom more than instructors in other countries in this study. (See Table 4). On the other hand, similar to what the learners' and the instructors' results revealed, they did not have experiences on mobile technologies as same as new generation students.

Table 4. Mobile Learning Technologies Experience of Instructors

\begin{tabular}{|c|c|c|c|}
\hline Countries & Yes & No & No Idea \\
\hline Belgium & 2 & 13 & 3 \\
\hline The Netherlands & 2 & 7 & 1 \\
\hline Spain & 5 & 1 & 2 \\
\hline Turkey & 3 & 12 & 1 \\
\hline
\end{tabular}

The instructors were also asked if they would prefer using mobile learning technologies in their courses (See Table 5). The results showed variations by country. All Spanish instructors were open for sharing their course materials on mobile platforms, while nearly half of instructors from Belgium were not. The participants from The Netherlands and Turkey were open for using mobile technologies for teaching. However, there was still a high percentage of instructors who were not open to this idea.

Table 5. Mobile Learning App Willingness of Instructors for Teaching

\begin{tabular}{|c|c|c|c|}
\hline Countries & Yes & No & No Idea \\
\hline Belgium & 7 & 7 & 4 \\
\hline The Netherlands & 5 & 3 & 2 \\
\hline Spain & 8 & 0 & 0 \\
\hline Turkey & 12 & 4 & 0 \\
\hline
\end{tabular}

The instructors were asked which ones they would prefer for teaching among digital learning materials such as videos, audios, educative games, etc. (See Table 6). This result is mainly the same as learners' preferences.
According to data, instructors from Spain use more variety of digital tools than other participants in other countries. In Spain, 5 out of 8 instructors experienced mobile learning technologies, which is the highest rate for utilization of digital technologies among the countries researched.

Table 6. ICT Tools Preferred by Instructors

\begin{tabular}{|c|c|}
\hline Countries & Instructors \\
\hline Belgium & video, audio and e-books \\
\hline The Netherlands & videos, audios and e-books \\
\hline Spain & $\begin{array}{c}\text { social networks/forums, audios, blogs, } \\
\text { educational games }\end{array}$ \\
\hline Turkey & videos, e-books and webinars \\
\hline
\end{tabular}

The learners believed that using mobile applications for educational purposes might give meaningful experiences for learning if they learn in their native language, except for the learners in The Netherlands. Most of the learners in The Netherlands strongly prefer the learning materials in English. The controversy observed in data from The Netherlands is probably due to higher education language in The Netherlands which is $100 \%$ English in most universities.

Table 7. Learning Language Preferred by Learners

\begin{tabular}{|c|c|c|c|}
\hline \multirow{2}{*}{ Countries } & \multicolumn{3}{|c|}{ Language Preference } \\
\cline { 2 - 4 } & $\begin{array}{c}\text { Native } \\
\text { language }\end{array}$ & English & $\begin{array}{c}\text { No } \\
\text { preference }\end{array}$ \\
\hline Belgium & 24 & 9 & 3 \\
\hline $\begin{array}{c}\text { The } \\
\text { Netherlands }\end{array}$ & 3 & 20 & 3 \\
\hline Spain & 27 & 2 & 4 \\
\hline Turkey & 32 & 17 & 1 \\
\hline
\end{tabular}

Instructors had slightly different thoughts on using mobile technologies in education. They believed that mobile technologies were critically important for educational purposes; however, they agreed that learning materials should be in their own language, with the exceptions of instructors from The Netherlands (Table 8).

Table 8. Learning Language Preferred by Instructors

\begin{tabular}{|c|c|c|c|}
\hline \multirow{2}{*}{ Countries } & \multicolumn{3}{|c|}{ Language Preference } \\
\cline { 2 - 4 } & $\begin{array}{c}\text { Native } \\
\text { language }\end{array}$ & English & No preference \\
\hline Belgium & 10 & 1 & 7 \\
\hline $\begin{array}{c}\text { The } \\
\text { Netherlands }\end{array}$ & 3 & 5 & 2 \\
\hline Spain & 7 & 1 & 0 \\
\hline Turkey & 11 & 2 & 3 \\
\hline
\end{tabular}

\subsection{Analysis of Open-ended Questions and Interviews}

\subsubsection{Learners Perspectives}

Learners were familiar with using technology and were able to use the mobile technologies for learning without 
any further education for a particular use. However, they preferred that the platform to be user-friendly and attractive, and the content to be accessible. Most of the learners mentioned that they were willing to follow courses by a mobile learning platform.

According to the interviews, learners highlighted three main expectations to use mobile technologies in their courses in all countries (Fig. 1). They believed that tools should be related to their learning process, should be familiar, and meet their personal needs. They also stated that all those expectations should be systematically related and covered with each other.

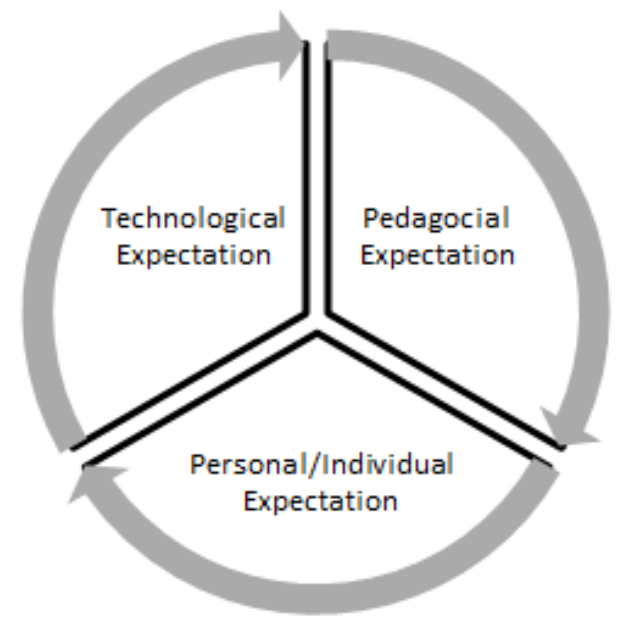

Figure 1. Learners' Perspectives

Some of the learners from different countries mentioned that

L1: "...the education program in our university is already full, so it would be easier to add ICT tools to existing courses for supporting learning"

L2: "I haven't used a mobile learning platform before but I think I can adopt easily"

L3: "I would prefer a mobile platform for learning if only it is designed in such a way that it is easy to use and has an attractive look-and feel to"

L4: "A mobile learning platform could be a useful tool depending on the design; it would be nice to have it available for tablet and desktop as well".

According to learners, they believed that mobile platforms and ICT tools are supportive technologies for learning. Therefore it is important to understand that digital materials do not only enrich learning process but also meet learners' expectations on teaching. Learners also thought that mobile platforms and materials were user-friendly, easy to use, and adoptable tools for learning. On the other hand, they highlighted that design process of mobile learning is critically important to use preferable tools.

\subsubsection{Instructors Perspectives}

Instructors provided valuable comments for their course contents during the interview. They thought that their courses should be supported by learning technologies and learning platforms which digital learning materials for different content of courses, they also stated that hands-on content details of the courses might not be given by a mobile application. They were also willing to share their course materials after solving copy-right issues. The data showed that instructors mentioned mainly two categories: Technological Competency and Pedagogical competency (Fig.2). They believed that instructors need to improve their technological and pedagogical skills to use mobile platforms and ICT tools effectively in their course. It is also mentioned that using ICT tools as digital materials is not the only important part of a whole course, teaching skills and integrating those tools into learning process efficiently are critically important parts of a course as skills too. The majority of instructors highlighted that there were limited digital tools to support their teaching and learning process. Therefore, this could be related to their technological competencies. On the other hand, it was mostly argued that teaching skills were important, however the new generation needs more knowledge on not only how to effectively teach but also how to efficiently teach by using technological tools.

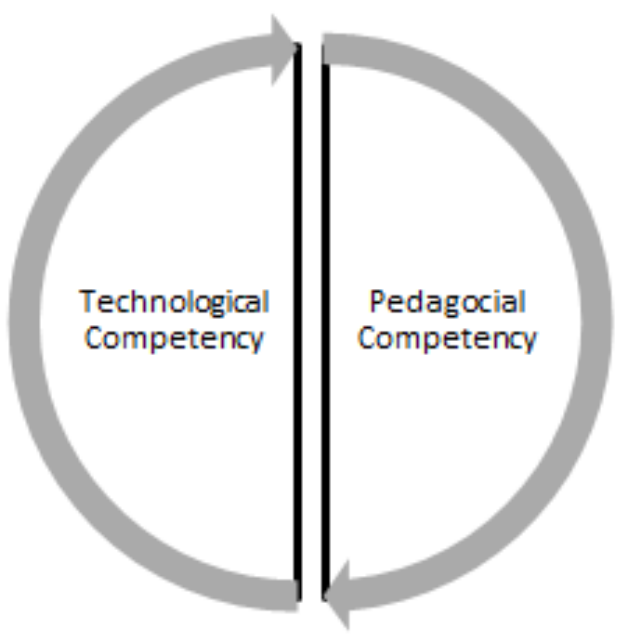

Figure 2. Instructors' Perspectives

I1: "I think ICT tools cannot be easily included in the formal curricula but can be adopted as supplementary course materials for different courses"

I2: "I can share my course notes. But, information's source that shared via this application should be controlled by a confidential institution".

I3: "I believe an additional training is necessary for the learners and that contents can be easily shared if there is a feasible sharing protocol within the mobile platform for them".

I4: "A mobile platform is good as a learning tool but, I feel that it may not be efficient enough for a detailed in-depth course." 
I5: "Almost all of my students can use communication technologies successfully. Even during the courses, they can't stand away from their mobile phones or tablets!"

I6: "The courses should support visuals such as diagrams, photos, videos and the e-learning platforms to be interactive”

Instructors mainly mentioned pedagogical and technical issues. They said that mobile learning increased learners' attention and supported a create-effective learning environment. However, they had some concerns with regards to the integration into their teaching process, institutional approval, and instructors' readiness to use mobile learning technologies. They also stated that the main purpose of using mobile technology in educational settings did not only facilitate learning process but also enriched educational process by sharing educational materials.

\section{Discussion}

\subsection{Awareness and Willingness on Mobile Learning Technologies}

When the awareness of the learners on mobile learning technologies was analysed, regardless of the survey country, 82 of 145 (57\%) learners have had previous experience with mobile learning platforms. Among the countries researched, a previous experience with mobile learning technology is the highest in Belgium (78\%), followed by The Netherlands (54\%), Spain (49\%) and Turkey $(48 \%)$, respectively. In order to analyse the instructors' awareness on mobile learning technologies, they were questioned if they had ever used a mobile platform for either learning or teaching. The next question was if they would prefer a mobile learning platform for their courses as a supportive tool. The results of these questions reveal that among 52 instructors surveyed, only 12 of them $(23 \%)$ had previous mobile learning technology experience. Awareness by country level is the highest in Spain (63\%). The Netherlands (20\%), Turkey (19\%) and Belgium (11\%) show lower levels. However, the willingness of all instructors, as well as their country-level distribution is higher than their awareness when they were questioned if they would like to use a mobile learning platform designed for their courses in the future. Among all instructors surveyed, 32 over 52 of them $(62 \%)$ would prefer to use mobile learning technologies for their courses; this ratio is $100 \%$ for Spain, $75 \%$ for Turkey, $50 \%$ for The Netherlands, and 39\% for Belgium. It is interesting to note that the Belgium learners are the ones with most awareness and knowledge on mobile learning technologies and ICT tools, but the instructors from Belgium have the lowest levels of awareness and willingness for using them for teaching.
ICT tool preferences of learners from different countries showed that irrespective of the country the most preferred tool is video, followed by others. Country level identification shows that the more the learners are aware of mobile learning technologies, the more complicated ICT tools they include in their preferences. Similarly, Spanish instructors who are the most aware ones on ICT tools prefer more complicated tools. The learners and instructors have the similar preferences as they prefer to use videos for learning/teaching followed by other ICT tools.

\subsection{Language Preferences for Mobile Learning Technologies}

Learners and instructors were asked in which language they would like their learning/teaching. Regardless of the country, 86 among 145 learners (59\%) and 31 among 52 instructors $(60 \%)$ prefer to use the ICT tools and content in their native language. Except for The Netherlands, learners' preference to learn in their native language is as follows; Spain (81\%) Belgium (66\%) Turkey (64\%), respectively. Similarly, the instructors prefer to teach via those tools in their native languages: Turkey (69\%), Belgium (56\%) and Spain (46\%). For The Netherlands, this is not the case, only 3 of 26 learners (11\%) and 3 of 10 instructors (30\%) prefer their native language, most of the learners and instructors think that teaching via those tools should be in English.

The language of the content is very important to understand the whole course. It is preferable to have all learning materials in native language. However, some universities in other countries where native language is not English might be teaching in English. If the teaching language in those universities is a hundred percent English, learners and instructors might tend to keep their learning process in English instead of their native language. Moreover, it might be a policy of some universities to use common academic language which is English in their institutions.

\subsection{Learners' Expectations and Instructors' Competencies}

Related to emerging technologies, learners' expectations have changed. The new generation can use technology more effectively than their instructors. Using educational technologies is one of the characteristics of digital learners. Digital learners would like to learn via educational technologies and/or technology-based media such as ICT tools in education, online courses, mobile applications and so on. Therefore, learners in this study mentioned that they expected to (i) have strong pedagogical approaches, (ii) reduce technological problems and (iii) encourage individual self-learning while using ICT tools in educations. It shows that learners still deal with same problems in different cultures. On the other hand, instructors stated similar issues. Moreover, they also 
mentioned their competencies as a technological challenge. Although learners believed that they could handle technological problems and manage their learning process via/by ICT tools, instructors had lack of self-confidence to use those technologies in learning environments effectively. That lack of self-confidence might affect students' learning process, therefore teachers need to use pedagogical techniques/approaches in ICT supported learning environments.

\section{Conclusions}

This exploratory mixed method study was aimed to understand the perspectives of learners and instructors in engineering education on mobile learning technologies in different countries. With minor cultural differences as discussed above, it can be concluded that the students have more awareness and previous experience with mobile technologies in comparison to instructors, but the instructors (independently whether they have previous experience or not) have the willing to include those technologies into their courses. Among the types of ICT tools, both learners and instructors would prefer to use videos for learning/teaching. Audios, e-books, social networks/forums, wikis, educational games are the other preferred tools selected by learners and instructors. Language preference of both learners and instructors points out that most of them would like to learn and teach in their native language. In contrast, a clear cultural difference was observed for the participants from The Netherlands (both instructors and learners) who prefer English instead of their native language. In-depth analysis of participants showed that both learners' and instructors' perspectives met, as the learners mainly indicated their technological, pedagogical and personal expectations while the instructors reflected their pedagogical and technological competencies, respectively.

Raising awareness about such tools especially for instructors is recommended because using educational technological technologies were limited to/by instructors' experiences. The willingness of instructors shows that if they had more information on diverse tools and technologies they would prefer to gain more experience in the future. The interest of students with regards to these technologies is satisfactory. It is very important to overcome fear of using new technologies in the classrooms and increase the readiness of using educational tools by integrating into their courses effectively. It is strongly recommended to design digital learning materials specific to course subjects collected in a virtual environment where they are accessible for all instructors and learners.

The ICT tools in educational settings have influences on both learners and instructors. However, students come with different and many expectations on having effective learning processes, nevertheless instructors deal with meeting those expectations by improving (or trying to improve) their abilities on using ICT tools for their teaching processes. A new generation was born in a new era where changes and challenges are mainly based on technology. They use new technologies in their academic, professional and private lives. This reality requires instructors to use those technologies in their classroom to enrich learning materials. However, there are limited or no materials in many specific contents, hence instructors have lack of sources to integrate those technologies in their content. It is very and critically important to have pools for digital learning materials in different fields and different languages. The ideal solution could be to have those digital material pools which are open and free for all learners, instructors, in-service professionals and people who would like to improve their knowledge on specific topics.

\section{Acknowledgements}

The study was carried under Energy Efficient Building Learning Application (nEBULA) project co-funded by the European Commission and Turkish National Agency under ERASMUS+ KA2 Strategic Partnerships for Higher Education Programme. The authors would like to thank the Management Committee members of nEBULA Consortium, Dr. Ninel ALVER from Ege University (Turkey), Kostas Sotiropoulos from ERGOMEC (Greece), Oğuzhan Çopuroğlu from Delft University of Technology (The Netherlands) and Joël Claes from UC Leuven-Limburg (UCLL) and to all contributing staff of the Consortium.

\section{REFERENCES}

[1] Accenture. New realities, new opportunities. Accenture chemical industry vision 2016. (2016); 1-24. Available from: https://www.accenture.com/t20160609T025416_w /us-en/ acnmedia/PDF-22/Accenture-Chemical-Vision-2 016.pdf

[2] Patil, A. New media communication skills for engineers and IT professionals, 1-3. (2012). Available from: https://doi.org/10.4018/978-1-4666-0243-4

[3] Sunthonkanokpong, W. Future global visions of engineering education. Procedia Engineering. (2011); 8: 160-164.

[4] Byers, T., Seelig, T., Sheppard, S., Weilerstein, P. Entrepreneurship its role in engineering education, The Bridge, Summer 2013 - v43n2. (2013). Available from: https://www.nae.edu/File.aspx?id=88638

[5] Felder, R. M., Woods, D. R., Stice, J. E., \& Rugarcia, A. The future of engineering education II. Teaching methods that work, Chemical Engineering Education, (2000); 34(1): 26-39. Available from: https://doi.org/10.1.1.34.1082

[6] Viegas, C., Marques, A., \& Alves, G. R. 21st Century 
challenges in engineering and technological learning. In Dodero, J. M. Ibarra Sáiz, M. S., Ruiz Rube \& I. (Eds.), Fifth International Conference on Technological Ecosystems for Enhancing Multiculturality (TEEM'17) (Cádiz, Spain, October 18-20, 2017) (Article 11). New York, NY, USA: ACM. (2017) doi:10.1145/3144826.3145 359

[7] Jansen, C., \& Van Der Merwe, P. Teaching Practice in the 21st Century: Emerging Trends, Challenges and Opportunities. Universal Journal of Educational Research. (2015); 3 (3): 190- 199. Available from: http://files.eric.ed.gov/fulltext/EJ1056080.pdf

[8] Feola, E.I. Digital Literacy and New Technological Perspectives, Universal Journal of Educational Research, (2016); v4 n9 p2174-2180.

[9] European Commission, Communication from the Commission to the European Parliament, The Council, The European Economic and Social Committee and The Committee of The Regions on the Digital Education Action Plan (DEAP), Brussels. (2018); Available from: https://ec.europa.eu/education/sites/education/files/digitaleducation-action-plan.pdf

[10] Fırat, M., Atila, O., Tanyeri, B., \& Varol, Y. Mühendislik eğitiminde uzaktan eğitimin kullanılması. Süleyman Demirel Üniversitesi Fen Bilimleri Enstitüsü Dergisi. (2013); 17(1).

[11] Kesim, M., \& Ozarslan, Y. (2012). Augmented reality in education: current technologies and the potential for education. Procedia-Social and Behavioural Sciences. (2012); 47: 297-302.

[12] Banday, M. T., Ahmed, M., \& Jan, T. R. Applications of e-Learning in engineering education: A case study. Procedia-Social and Behavioural Sciences. (2014); 123. 406-413.
[13] Jones, C. A new generation of learners? The net generation and digital natives. Learning, Media and Technology. (2010); 35(4): 365-368. Available From: https://doi.org/10.1080/17439884.2010.531278

[14] Jadhav, M. R., Kakade, A. B., \& Patil, M. S. ICT and Active Teaching-Learning- Assessment Process in the Engineering Education. (2018); 31(3): 1-5.

[15] Martin, J. L., Frias, Z., \& Martinez, J. P. Can learning methodologies contribute to develop digital competences in telecommunication engineering education? 2017 56th FITCE Congress, FITCE 2017. (2017); 45-49. Available from: https://doi.org/10.1109/FITCE.2017.8093006

[16] Long, Y., Zhang, M., \& Qiao, W. Online engineering internet of things. (2018); 22. Available from: https://doi.org/10.1007/978-3-319-64352-6

[17] Martín, S., Castro, M., Cukierman, U., Meier, R. \& Waigandt, D. ICT needs and trends in engineering education. 2015 International Conference on Interactive Collaborative Learning (ICL), At Florence (Italy). (2015).

[18] Andiç-Çakır, Ö., Alver, N. \& Leeuwen, M. NEBULA Energy efficient building learning application, Project, Intellectual Output 1 Report, Methodology for Needs Analysis, Project funded under EU ERASMUS+ Program, no: 2014-1-TR01-KA203- 013102 (2016). Available from: http://n-ebula.eu/wp-content/uploads/2015/03/NEBULA-I O1-V1_11042016_final-version.pdf

[19] Andiç-Çakır, Ö., Alver, N. \& Leeuwen, M. NEBULA Energy efficient building learning application, Project, Intellectual Output 2 Report, Needs Analysis Report (Aggregated), Project funded under EU ERASMUS+ Program, no: 2014-1-TR01-KA203- 013102. (2016). Available from: http://n-ebula.eu/wp-content/uploads/2015 /03/NEBULA-IO2-V3 14042016 final-version reviewed. pdf 